\title{
COMPORTAMENTO RUMINAL DE TOURINHOS ALIMENTADOS COM DIETAS DE GRAMÍNEA E CONCENTRADO COMERCIAL SUPLEMENTADAS COM HIBISCO E Sacharina
}

\author{
Gaspar Pinzón Almeida, ${ }^{1}$ Emilio Manuel Aranda-Ibáñez, ${ }^{2}$ Jorge Pérez Pérez, ${ }^{3}$ \\ Hernández Garay Alfonso, ${ }^{4}$ Ives Cláudio da Silva Bueno ${ }^{5}$ e André César Vitti ${ }^{6}$ \\ 1. Campus Tabasco Colegio de Postgraduados, México \\ 2. Campus Tabasco Colegio de Postgraduados, México. E-mail: earanda@colpos.mx \\ 3. Campus Tabasco Colegio de Postgraduados, México \\ 4. Campus Tabasco Colegio de Postgraduados, México \\ 5. Faculdade de Zootecnia e Engenharia de Alimentos, Universidade de São Paulo \\ 6. Polo Centro Sul, Agência Paulista de Tecnologia dos Agronegócios.
}

\section{RESUMO}

Com o objetivo de avaliar hibisco e sacharina como suplementos para tourinhos, quatro animais cruzados foram distribuídos em um delineamento experimental de quadrado latino. Os tratamentos foram: $1-75 \%$ pasto $+25 \%$ concentrado; $2-50 \%$ pasto $+25 \%$ concentrado $+25 \%$ hibisco; $3-50 \%$ pasto $+25 \%$ concentrado $+25 \%$ sacharina; e $4-25 \%$ pasto $+25 \%$ concentrado $+25 \%$ hibisco $+25 \%$ sacharina. Foram avaliadas a composição das dietas, a fermentação ruminal e as taxas de degradação da MS e da PB. Os valores de $\mathrm{pH}$ ruminal variaram de 5,82 a 6,98 - para as dietas suplementadas com hibisco, 9 horasoras após a alimentação e, com sacharina, no momento da alimentação. Os teores de $\mathrm{N}$ amoniacal não tiveram grandes alterações quando apenas hibisco ou sacharina foram acrescidos à dieta, mas houve efeito significativo quando ambos foram acrescentados $(\mathrm{P}>0,001)$. A concentração de ácidos graxos de cadeia curta no líquido ruminal diminuiu em virtude da presença de sacharina na dieta $(\mathrm{P}<0,01)$. A dieta com sacharina apresentou maior fração prontamente solúvel da MS e da $\mathrm{PB}(\mathrm{P}<0,01)$. A sacharina promoveu maior efeito na degradação da MS das dietas totais $(\mathrm{P}<0,05)$. A inclusão de hibisco e de sacharina aumentou a degradação das dietas de tourinhos alimentados a pasto $(\mathrm{P}<0,05)$. Ao incluir esses alimentos, o ambiente e a funcionalidade ruminal foram melhorados. Considera-se viável, na suplementação, a substituição parcial do concentrado pelos alimentos testados.

PALAVRAS-CHAVES: Fermentação ruminal, taxa de degradação, degradabilidade.

\section{ABSTRACT}

\section{RUMEN CHARACTERISTICS OF YOUNG BULLS FED DIETS BASED ON GRASS AND COMMERCIAL CONCENTRATE SUPPLEMENTED WITH Hibiscus rosa-sinensis AND Sacharina}

Aiming at evaluating hibiscus (Hibiscus rosa-sinensis) and sacharina as supplements for young bulls, four crossbred animals were displayed in a Latin square experimental design. The following treatments were performed: $1-75 \%$ pasture $+25 \%$ concentrate; $2-50 \%$ pasture $+25 \%$ concentrate $+25 \%$ hibiscus; $3-50 \%$ pasture $+25 \%$ concentrate $+25 \%$ saccharina; and $4-25 \%$ pasture $+25 \%$ concentrate $+25 \%$ hibiscus $+25 \%$ saccharina. Diet composition, rumen fermentation, DM and CP degradation rates were evaluated. Rumen $\mathrm{pH}$ values varied from 5.82 to 6.98 , for diets supplemented with hibiscus, at $9 \mathrm{~h}$ post-feeding, and with saccharina, at the feeding moment. Ammonia $\mathrm{N}$ contents did not present great changes when only hibiscus or saccharina were added to the diet, but there was a significant effect when both were added $(\mathrm{P}<0.001)$. Rumen SCFA concentrations were lower due to saccharine presence in the diet $(\mathrm{P}<0.01)$. Sacharina diet presented higher values for readily soluble fraction for $\mathrm{DM}$ and $\mathrm{CP}(\mathrm{P}<0.01)$. Sacharina promoted a higher effect on DM degradation of total diets $(\mathrm{P}<0.05)$. Hibiscus and saccharina inclusion increased the 
degradation of diets for grazing young bulls $(\mathrm{P}<0.05)$. Including these feed to the concentrate, the rumen environment

KEYWORDS: Rumen fermentation, degradation rate, degradability.

\section{INTRODUÇÃO}

A alimentação de ruminantes nas regiões tropicais do México é feita à base de pastos de baixa qualidade, os quais são ricos em fibras e deficientes em proteína e energia, e, isoladamente, durante parte do ano, são capazes apenas de promover baixos níveis de produção. Além disso, a pecuária nessas áreas apresenta problemas graves devido à carência de forragem, ocasionada pelas fortes secas ou inundações. A falta de chuvas faz com que os pastos percam qualidade, devido à redução de folhas e aumento do teor de fibras. Consequentemente, ocorrem perdas de peso nos animais e, em condições severas, alguns deles podem morrer principalmente os mais jovens (ALAYÓN et al., 1998).

No trópico mexicano, a engorda dos animais desmamados pode ser feita com uso de árvores e arbustos forrageiros ou de cana-de-açúcar (ARANDA-IBÁÑEZ \& OSORIO, 2003). A integração de árvores e arbustos à alimentação melhora o ganho de peso dos animais, devido ao fato de as folhas dessas plantas terem alto teor proteico. Existe no México uma grande variedade de espécies de árvores e arbustos que tem potencial para serem incorporados aos sistemas de produção de ruminantes nos trópicos. Uma delas é o hibisco, conhecido no México como tulipán, cujo nome científico é Hibiscus rosa-sinensis, que tem sido testado em algumas regiões como alimento para ruminantes em virtude de sua boa qualidade nutricional.

No entanto, a cana-de-açúcar é indiscutivelmente considerada como recurso forrageiro com potencial estratégico para épocas de seca, pois, nas regiões tropicais, existem condições favoráveis para que apresente alto rendimento de matéria seca (MS), em comparação com outras forragens. Essa planta possui uma grande quantidade de carboidratos solúveis, em forma preponderante de sacarose, mas com baixo teor de proteína bruta (PB), ao redor de $2,5 \%$. Contudo, pode-se obter a cana enriquecida, ou sacharina, mediante a fermentação aeróbica, em estado sólido, da cana-de-açúcar limpa (livre de folhas e de ponta) e moída combinada com ureia e sais minerais. Ela contém compostos nitrogenados proteicos e não proteicos obtidos pelo incremento da and functionality were improved. Thus, it is viable the partial replacement of concentrate by the tested feed. massa microbiana. Seu teor de proteína verdadeira é de $11 \%$ a $16 \%$ de MS (ELÍAS et al., 1990).

Sendo assim, objetivou-se com este estudo determinar as taxas de degradação dos alimentos e a fermentação ruminal de tourinhos alimentados com diversas combinações de pasto, hibisco, sacharina e suplemento concentrado.

\section{MATERIAL E MÉTODOS}

Animais e dietas

Foram utilizados quatro tourinhos $\left(\mathrm{F}_{1}\right.$ : Pardo Suíço x Brahman), de aproximadamente dois anos de idade, fistulados no rúmen com cânulas flexíveis permanentes, durante quatro períodos de 21 dias, dos quais 14 foram para adaptação e 7 para as medições e coletas de amostras. Os animais estiveram alojados em baias individuais, sendo alimentados com dois diferentes tratamentos e tendo livre acesso à água e ao sal mineralizado. A alimentação, fornecida uma vez ao dia, foi composta por capim-estrela-africana (Cynodon plectostachyus) e concentrado, com ou sem a adição de hibisco e sacharina. O capim e o hibisco foram colhidos de piquetes e oferecidos frescos aos animais (teor de MS de 29,56\% e $23,66 \%$ para capim e hibisco, respectivamente).

\section{Tratamentos}

Avaliaram-se quatro dietas, sendo elas:

- Dieta $1-75 \%$ pasto $+25 \%$ concentrado;

- Dieta $2-50 \%$ pasto $+25 \%$ concentrado $+25 \%$ hibisco;

- Dieta $3-50 \%$ pasto $+25 \%$ concentrado $+25 \%$ sacharina; e

- Dieta $4-25 \%$ pasto $+25 \%$ concentrado $+25 \%$ hibisco $+25 \%$ sacharina.

Variáveis avaliadas

A taxa e a extensão da degradação ruminal da MS e da PB foram medidas pela técnica in situ (ØR- 
SKOV et al., 1980), usando os tourinhos alimentados com as dietas experimentais. Os sacos de nylon com as amostras de capim-estrela-africana, hibisco, sacharina, concentrado e dietas totais, de acordo com os tratamentos, foram incubados, em duplicata, por 3, 6, 12, 24, 48, 72, 96 e 120 horas. Depois da incubação, lavaram-se os sacos em lavadora doméstica, várias vezes, até que a água saísse limpa. Os sacos foram, então, secos em estufa com circulação forçada de ar, a $60{ }^{\circ} \mathrm{C}$, por 48 horas.

O desaparecimento da MS e da PB dos alimentos e das dietas totais foi calculado como a diferença entre o material originalmente incubado e o material residual. Os dados de desaparecimento ruminal foram ajustados pelo modelo exponencial proposto por ØRSKOV \& McDONALD (1979) e modificado por McDONALD (1981) sendo $p=A$, para $t<t_{0}$; e $p=$ $a+b\left(1-\exp ^{-c t}\right)$, para $t>t 0$, em que $p$ é a degradabilidade no tempo $t ; A$ é a solubilidade inicial, ou fração prontamente solúvel; $t_{0}$ é o tempo de colonização (lag time); $a$ e $b$ são constantes matemáticas do modelo; e $c$ é a taxa de degradação. Desse modelo deriva-se $B$ $=(a+b)-A$, no qual $B$ corresponde à fração insolúvel degradável e a degradablidade potencial é dada pela soma das frações $A$ e $B$. O teor de proteína bruta foi determinado pelo método de micro-Kjeldahl.

Para o $\mathrm{pH}$ ruminal, o líquido ruminal foi coletado do saco ventral às $0,3,6$ e 9 horas após o fornecimento das dietas. Nessas amostras, o $\mathrm{pH}$ ruminal foi medido com potenciômetro modelo 10 Fisher Scientific.

Depois de medir o $\mathrm{pH}$ ruminal, $4 \mathrm{~mL}$ do líquido ruminal foram amostrados, acidificados com $1 \mathrm{~mL}$ de ácido metafosfórico concentrado a 25\% (peso:volume) e armazenados sob congelamento até posteriores análises de concentrações de $\mathrm{N}$ amoniacal e ácidos graxos de cadeia curta (AGCC): acetato, propionato e butirato. Determinaram-se as concentrações de $\mathrm{N}$ amoniacal pelo método do indofenol (McCULLOUGH, 1967), utilizando um espectrofotômetro Perkin Elmer Lambda 25, e dos AGCC, por cromatografia gasosa (ERWIN et al., 1961), com uso de um cromatógrafo Varian Star.

\section{Delineamento experimental}

Os dados foram analisados como um quadrado latino $4 \times 4$, com quatro animais e quatro períodos (STEEL \& TORRIE, 1980), por meio do procedimento GLM do pacote estatístico SAS (2001). Analisaram-se as variáveis que compõem os produtos da fermentação ruminal como medidas repetidas no tempo.

\section{RESULTADOS E DISCUSSÃO}

A composição química dos alimentos utilizados é apresentada na Tabela 1. Os teores de proteína bruta, proteína verdadeira (PV) e fração solúvel da MS foram mais baixos para o capim-estrela-africana. Já os teores de fibra em detergente neutro, fibra em detergente ácido e hemicelulose foram mais altos para esse capim. $\mathrm{O}$ concentrado apresentou os maiores teores de PB e PV. Os valores altos de proteína apresentados pela sacharina foram efeito da fermentação aeróbica das leveduras que se encontram naturalmente na cana-de-açúcar e da adição de ureia e sulfato de amônio, farelo de soja e sorgo.

TABELA 1. Composição química dos ingredientes e das dietas utilizadas

\begin{tabular}{|c|c|c|c|c|c|c|c|c|}
\hline \multirow[b]{2}{*}{ Alimentos } & \multicolumn{8}{|c|}{ Fração ${ }^{(1)}$} \\
\hline & MS & $\mathrm{PB}$ & PV & FDN & FDA & Hem & $\mathrm{MO}$ & $\mathrm{A}_{\mathrm{MS}}$ \\
\hline Capim-estrela-africana & 29,56 & 10,73 & 9,44 & 75,24 & 44,65 & 30,59 & 92,78 & 17,14 \\
\hline Hibisco & 23,66 & 13,51 & 11,89 & 35,10 & 21,26 & 13,85 & 93,00 & 33,83 \\
\hline Sacharina & 39,86 & 17,27 & 15,20 & 37,25 & 20,02 & 17,23 & 95,75 & 30,19 \\
\hline Concentrado & 90,14 & 22,85 & 20,11 & 34,02 & 7,51 & 26,52 & 94,68 & 22,38 \\
\hline $\operatorname{Dietas}^{(2)}$ & & & & & & & & \\
\hline Dieta 1 & 44,71 & 13,76 & 12,11 & 64,93 & 35,36 & 29,57 & 93,26 & 18,45 \\
\hline Dieta 2 & 43,23 & 14,46 & 12,72 & 54,90 & 29,52 & 25,39 & 93,31 & 22,62 \\
\hline Dieta 3 & 47,28 & 15,40 & 13,55 & 55,44 & 29,21 & 26,23 & 94,00 & 21,71 \\
\hline Dieta 4 & 45,81 & 16,09 & 14,16 & 45,40 & 23,36 & 22,05 & 94,05 & 25,89 \\
\hline
\end{tabular}

(1) MS: matéria seca (\% da matéria original); PB: proteína bruta (\% MS); PV: proteína verdadeira (\% MS); FDN: fibra em detergente neutro (\% MS); FDA: fibra em detergente ácido (\% MS); Hem: hemicelulose (\% MS); MO: matéria orgânica (\% MS); $\mathrm{A}_{\mathrm{MS}}$ : fração prontamente solúvel da MS.

(2) Dieta 1: $75 \%$ pasto $+25 \%$ concentrado; dieta $2: 50 \%$ pasto $+25 \%$ concentrado $+25 \%$ hibisco; dieta $3: 50 \%$ pasto $+25 \%$ concentrado $+25 \%$ sacharina; e dieta $4: 25 \%$ pasto $+25 \%$ concentrado $+25 \%$ hibisco $+25 \%$ sacharina. 
Os valores de PB e PV da sacharina chamam a atenção. Eles podem ser explicados pelo modo como esse alimento é processado. No México, país onde foi realizado o experimento, a sacharina é produzida com a mistura de 68,7\% de cana-de-açúcar (colmos desfolhados moídos), $1,5 \%$ de ureia, $0,5 \%$ de mistura mineral, $0,3 \%$ de sulfato de amônio, $5 \%$ de Vitafert $^{\circledR}$ (cultivo de lactobacilos vivos), e ainda $4 \%$ de farelo de soja e $20 \%$ de farelo de sorgo. Essa mistura de ingredientes, fermentada em presença de ar, por cerca de 24 horas, aumenta o teor proteico e eleva a qualidade da proteína.

A matéria orgânica foi similar para os quatro alimentos. $\mathrm{O}$ hibisco e a sacharina apresentaram os mais baixos níveis de hemicelulose, e os mais altos da fração solúvel de matéria seca. Esses resultados refletiram-se nas dietas, pois hibisco e sacharina aumentaram os teores de PB, PV e na fração prontamente solúvel da $\mathrm{MS}\left(\mathrm{A}_{\mathrm{MS}}\right)$, e diminuíram os teores das diferentes frações fibrosas.

$\mathrm{O}$ pH ruminal nos diferentes tempos após a alimentação é apresentado na Tabela 2 . O pH ruminal diminui com o decorrer do tempo após a alimentação, mas o pH às 6 e às 9 horas, com a suplementação de sacharina, é mais alto que o da dieta 1 . Esses valores estão associados à concentração de $\mathrm{N}$ amoniacal e de AGCC, que na dieta com sacharina foram menores para aqueles horários. Esse efeito da concentração de AGCC na diminuição do $\mathrm{pH}$ foi relatado por RUSSEL (1998).

Observaram-se os valores de $\mathrm{pH}$ mais elevados imediatamente antes da alimentação (tempo 0), e, posteriormente, foram decrescendo com o passar do tempo, até alcançar os níveis mais baixos às 9 horas após a alimentação.

Assim como a inclusão de sacharina, a de hibisco também aumentou a concentração de $\mathrm{N}$ amoniacal (Tabela 2). Foi ainda observado o efeito da interação entre a sacharina e o hibisco. Ao se adicionar a sacharina ou o hibisco, não houve alteração na concentração de $\mathrm{N}$ amoniacal. No entanto, a concentração diminuiu quando ambos foram acrescentados à dieta. Esse efeito pode estar relacionado com as taxas de degradação da parte solúvel da proteína da sacharina e do hibisco (Tabela 7). Todas as dietas alcançaram máxima concentração de $\mathrm{N}$ amoniacal às 3 horas após a alimentação, diminuindo posteriormente.

A concentração de ácidos graxos de cadeia curta do líquido ruminal diminuiu em virtude da presença de sacharina na dieta. Também houve efeito da interação entre a sacharina e o hibisco, sendo que, nas dietas sem sacharina, o hibisco aumentou a concentração de AGCC no líquido ruminal. Contudo, nas dietas com sacharina, essa concentração diminuiu, quando foi acrescentado o hibisco. Também se observou que os valores variaram com o tempo após a alimentação (Tabela 2): as concentrações mais baixas foram observadas para o tempo $0 \mathrm{e}$ às 3 horas pós-prandiais, aumentando gradativamente até as 9 horas.

As alterações na concentração de AGCC estão relacionadas ao tipo de dieta e às taxas de degradação do alimento. A sacharina apresentou menor taxa de degradação que o hibisco (Tabela 4).

Nas dietas (Tabela 2), não houve efeito da sacharina, do hibisco ou do tempo na proporção de ácido acético ruminal. Os valores variaram de 63,8\% a $69,3 \%$. O mesmo foi observado para a proporção de ácido propiônico, que variou de $18,0 \%$ a $20,5 \%$.

Para o ácido butírico, não houve efeito nem da sacharina nem do hibisco, mas houve uma interação entre o hibisco e o tempo, sendo que as dietas com hibisco foram superiores no tempo 0 e às 3 horas, e iguais às outras nos demais horários. Também houve uma tripla interação entre a sacharina, o hibisco e o tempo, na qual, nos tempos 0 e 3 horas, para as dietas sem sacharina, a adição de hibisco aumentou a concentração de ácido butírico; no entanto, não houve diferença para as dietas com sacharina. Às 6 e às 9 horas, não houve diferença para a sacharina ou para o hibisco.

A relação acetato:propionato não variou por efeito da sacharina, do hibisco ou do tempo após a alimentação.

Os produtos finais da fermentação ruminal dependem da dieta, e a relação acetato:propionato normalmente é mais baixa para os alimentos concentrados (cereais) que para as forragens (BLAXTER, 1962). Quando essa relação diminui, a produção de metano $\left(\mathrm{CH}_{4}\right)$ diminui e a retenção de energia para o animal é aumentada (WOLIN, 1960). Algumas bactérias ruminais, digestoras de amido, produzem quantidades significativas de propionato, mas muitas bactérias fibrolíticas produzem grandes quantidades de succinato, um intermediário que eventualmente é convertido em propionato (HUNGATE, 1966). A fermentação dos grãos de cereais muitas vezes causa uma redução no $\mathrm{pH}$ ruminal, e esse fato é mais dramático quando o 
consumo de alimento é alto (SLYTER, 1966). O lactato pode ser um intermediário na conversão de amido em propionato (HUNGATE, 1966). Quando o $\mathrm{pH}$ é menor que 5,3, a relação acetato:propionato é aumentada dramaticamente e também aumenta a quantidade de $\mathrm{H}_{2}$. Esses resultados indicam que as bactérias que produzem propionato podem ser muitas vezes mais sensíveis ao $\mathrm{pH}$ que as bactérias que produzem acetato e $\mathrm{H}_{2}$ (RUSSELL, 1998).

TABELA 2. Variáveis da fermentação ruminal de tourinhos fistulados alimentados com capim-estrela-africana (Cynodon plectostachyus) e concentrado, e suplementados com hibisco ou sacharina

\begin{tabular}{|c|c|c|c|c|c|c|c|c|}
\hline \multirow{3}{*}{$\operatorname{Dieta}^{(1)}$} & \multirow{3}{*}{ Tempo } & \multicolumn{7}{|c|}{ Variáveis } \\
\hline & & \multirow{2}{*}{$\mathrm{pH}$} & $\mathrm{N}-\mathrm{NH}_{3}$ & AGCC & Acetato & Propionato & Butirato & Relação \\
\hline & & & $\mathrm{mg} / \mathrm{dl}$ & $\mathrm{mmol} / \mathrm{l}$ & $\%$ & $\%$ & $\%$ & acet: prop \\
\hline \multirow{5}{*}{ Dieta 1} & $0 \mathrm{~h}$ & 6,68 & 23,04 & 71,26 & 68,30 & 18,32 & 12,71 & 3,65 \\
\hline & $3 \mathrm{~h}$ & 6,41 & 34,04 & 76,84 & 67,89 & 18,04 & 13,14 & 3,66 \\
\hline & $6 \mathrm{~h}$ & 5,84 & 28,36 & 73,94 & 66,52 & 18,44 & 14,05 & 3,47 \\
\hline & $9 \mathrm{~h}$ & 5,85 & 20,31 & 78,32 & 67,31 & 18,38 & 13,88 & 3,67 \\
\hline & $\mathrm{EPM}^{(2)}$ & 0,17 & 1,33 & 2,09 & 0,51 & 0,72 & 0,79 & 0,13 \\
\hline \multirow{5}{*}{ Dieta 2} & $0 \mathrm{~h}$ & 6,63 & 27,87 & 72,40 & 66,84 & 18,86 & 14,26 & 3,64 \\
\hline & $3 \mathrm{~h}$ & 6,31 & 31,22 & 84,06 & 63,83 & 20,59 & 14,59 & 3,02 \\
\hline & $6 \mathrm{~h}$ & 5,87 & 29,19 & 90,49 & 65,75 & 20,07 & 13,62 & 3,23 \\
\hline & $9 \mathrm{~h}$ & 5,82 & 25,33 & 87,22 & 66,59 & 20,16 & 13,45 & 3,36 \\
\hline & $\mathrm{EPM}^{(2)}$ & 0,16 & 1,55 & 5,25 & 1,42 & 0,90 & 0,61 & 0,21 \\
\hline \multirow{5}{*}{ Dieta 3} & $0 \mathrm{~h}$ & 6,98 & 24,11 & 63,99 & 68,40 & 18,80 & 12,80 & 3,65 \\
\hline & $3 \mathrm{~h}$ & 6,55 & 34,33 & 62,27 & 69,32 & 18,24 & 12,44 & 3,82 \\
\hline & $6 \mathrm{~h}$ & 6,49 & 29,55 & 71,78 & 68,01 & 18,69 & 13,31 & 3,66 \\
\hline & $9 \mathrm{~h}$ & 6,39 & 27,73 & 72,67 & 67,85 & 18,57 & 13,58 & 3,69 \\
\hline & $\mathrm{EPM}^{(2)}$ & 0,16 & 2,40 & 5,15 & 1,37 & 0,98 & 0,64 & 0,23 \\
\hline \multirow{5}{*}{ Dieta 4} & $0 \mathrm{~h}$ & 6,75 & 15,85 & 62,29 & 68,48 & 19,48 & 12,04 & 3,52 \\
\hline & $3 \mathrm{~h}$ & 6,44 & 19,28 & 53,94 & 68,41 & 18,95 & 12,65 & 3,65 \\
\hline & $6 \mathrm{~h}$ & 6,20 & 18,02 & 55,62 & 67,89 & 18,85 & 13,26 & 3,65 \\
\hline & $9 \mathrm{~h}$ & 6,04 & 16,62 & 63,52 & 67,34 & 19,60 & 13,07 & 3,47 \\
\hline & $\mathrm{EPM}^{(2)}$ & 0,05 & 2,60 & 5,55 & 0,90 & 0,78 & 0,46 & 0,21 \\
\hline \multicolumn{9}{|l|}{ Efeitos } \\
\hline \multicolumn{2}{|l|}{ Sacharina } & $*$ & $* *$ & $* *$ & ns & ns & ns & ns \\
\hline \multicolumn{2}{|l|}{ Hibisco } & ns & $* *$ & ns & ns & ns & ns & ns \\
\hline \multicolumn{2}{|c|}{ Tempo } & $* * *$ & $* *$ & $*$ & ns & ns & ns & ns \\
\hline \multicolumn{2}{|c|}{ Sacharina $x$ hibisco } & ns & $* * *$ & $*$ & ns & ns & ns & ns \\
\hline \multicolumn{2}{|c|}{ Sacharina $x$ tempo } & ns & ns & ns & ns & ns & ns & ns \\
\hline \multicolumn{2}{|c|}{ Hibisco $x$ tempo } & ns & ns & ns & ns & ns & $*$ & ns \\
\hline \multicolumn{2}{|c|}{ Sacharina $x$ hibisco $x$ tempo } & ns & ns & ns & ns & ns & $*$ & ns \\
\hline
\end{tabular}

(1) Dieta 1: $75 \%$ pasto $+25 \%$ concentrado; dieta $2: 50 \%$ pasto $+25 \%$ concentrado $+25 \%$ hibisco; dieta $3: 50 \%$ pasto $+25 \%$ concentrado $+25 \%$ sacharina; e dieta $4: 25 \%$ pasto $+25 \%$ concentrado $+25 \%$ hibisco $+25 \%$ sacharina.

(2) $\mathrm{EPM}=$ erro padrão da média; $\mathrm{ns}=$ não significativo $(\mathrm{P}>0,05) ;{ }^{*}=\mathrm{P} \leq 0,05 ; * *=\mathrm{P} \leq 0,01 ; * * *=\mathrm{P} \leq 0,001$.

TAMMINGA (1992) estimou que 50\% do $\mathrm{N}$ da dieta são perdidos pelo ruminante (no caso de vacas leiteiras) pela excreção urinária. Desses $50 \%$, aproximadamente $30 \%$ são perdidos devido ao metabolismo ineficiente do rúmen. Além disso, a utilização eficiente da amônia no rúmen é um fator central que determina os custos econômicos e o impacto ambiental da produção de ruminantes (HRISTOV et al., 2003). Se não é utilizada para a produção de massa microbiana, a amônia ruminal se detoxifica no fígado (LOBLEY et al., 1995) e uma porção significativa dela é perdida através da excreção da ureia urinária.

Em alguns estudos (CECAVA et al., 1990), a alimentação com fontes de proteína suscetíveis de degradação ruminal aumentou a eficiência da síntese 
de proteína microbiana e/ou o fluxo de $\mathrm{N}$ microbiano no intestino delgado, em comparação com proteínas mais resistentes à degradação ruminal. Essas condições podem ser devidas ao aumento da concentração de $\mathrm{N}$ amoniacal e/ou aos produtos da quebra da proteína, necessários para o crescimento microbiano (HESPELL, 1979). Na maioria dos casos, os efeitos das concentrações dos fatores de crescimento da proteólise na síntese de proteína são confundidos com as concentrações ruminais de $\mathrm{N}$ amoniacal. A eficiência do rendimento e o crescimento microbiano também são afetados pela quantidade de matéria orgânica fermentada no rúmen (ROHR et al., 1986). Teoricamente, as concentrações adequadas de $\mathrm{N}$ amoniacal podem maximizar o crescimento microbiano se as concentrações de outros nutrientes são insuficientes para isso (CECAVA et al., 1991).

As dietas com concentrado, baseadas em milho, podem aumentar a disponibilidade de energia em todos os locais do trato gastrointestinal, pelo fato de ser mais provável o aumento do suprimento de carboidratos não estruturais (amido) (CECAVA et al., 1991). A amônia é a fonte de $\mathrm{N}$ preferida pelas bactérias fibrolíticas (HUNGATE, 1966) e também é necessária às fermentadoras de amido para a síntese de proteína microbiana (COTTA \& RUSSEL, 1982). SCHAEFER et al. (1980) relataram que não mais que $5 \mathrm{mg} / \mathrm{dl}$ de $\mathrm{N}$ amoniacal são necessários para o máximo crescimento microbiano. Porém, WALLACE (1979) observou que as taxas aumentadas de degradação in situ da MS e da PB de grãos de cevada foram acompanhadas pelo crescimento bacteriano, aumentando quando a concentração de $\mathrm{N}$ amoniacal passou de 9,7 a $21,4 \mathrm{mg} / \mathrm{dl}$ de fluido ruminal. Do mesmo modo, MEHREZ et al. (1977) relataram que as taxas de degradação in situ foram maximizadas em concentrações de $\mathrm{N}$ amoniacal acima de $20 \mathrm{mg} / \mathrm{dl}$ de fluido ruminal.

As constantes de degradação ruminal da matéria seca encontradas para o pasto de capim-estrela-africana, usado como base das dietas dos animais, são apresentadas na Tabela 3. Em nenhuma das constantes de degradação ruminal da MS foi observado efeito da sacharina ou do hibisco.

TABELA 3. Constantes de degradação ruminal da MS do capim-estrela-africana (Cynodon plectostchyus) por animais alimentados com as quatro dietas ${ }^{(1)}$ experimentais

\begin{tabular}{|c|c|c|c|c|c|c|}
\hline \multirow{2}{*}{ Alimentação dos animais ${ }^{(1)}$} & \multicolumn{6}{|c|}{ Variáveis $^{(2)}$} \\
\hline & A & $\mathrm{B}$ & $\mathrm{A}+\mathrm{B}$ & $\mathrm{c}$ & $\mathrm{t}_{0}$ & $\mathrm{DE}$ \\
\hline Dieta 1 & 18,67 & 45,73 & 64,39 & 0,0347 & $-1,48$ & 35,28 \\
\hline Dieta 2 & 19,88 & 49,08 & 68,96 & 0,0266 & $-2,98$ & 34,54 \\
\hline Deita 3 & 22,49 & 47,35 & 69,84 & 0,0334 & $-1,80$ & 38,99 \\
\hline Dieta 4 & 22,88 & 46,03 & 68,89 & 0,0259 & $-3,58$ & 36,35 \\
\hline $\begin{array}{l}\mathrm{EPM}^{(3)} \\
\text { Efeitos }\end{array}$ & 1,52 & 1,47 & 1,80 & 0,0067 & 1,20 & 1,47 \\
\hline Sacharina & ns & ns & ns & ns & ns & ns \\
\hline Hibisco & ns & ns & ns & ns & ns & ns \\
\hline Sacharina $x$ hibisco & ns & ns & ns & ns & ns & ns \\
\hline
\end{tabular}

(1) Dieta 1: $75 \%$ pasto $+25 \%$ concentrado; dieta $2: 50 \%$ pasto $+25 \%$ concentrado $+25 \%$ hibisco; dieta $3: 50 \%$ pasto $+25 \%$ concentrado $+25 \%$ sacharina; e dieta $4: 25 \%$ pasto $+25 \%$ concentrado $+25 \%$ hibisco $+25 \%$ sacharina

(2) A: fração prontamente solúvel (\%); B: fração insolúvel fermentecível (\%); A+B: fração potencialmente degradável (\%); c: taxa de degradação; $\mathrm{t}_{0}$ : tempo de colonização (h); DE: degradabilidade efetiva (\%).

(3) $\mathrm{EPM}=$ erro padrão da média; $\mathrm{ns}=$ não significativo $(\mathrm{P}>0,05)$.

As taxas de degradação da MS da sacharina, do hibisco e do concentrado são expostas na Tabela 4. A sacharina apresentou os maiores valores da fração prontamente solúvel $(A)$, e o hibisco, os valores mais altos da fração insolúvel fermentescível $(B)$, e da taxa de degradação $(c)$. O concentrado foi o que apresentou maior potencial de degradação $(A+B)$.

As frações prontamente solúveis $(A)$ e potencialmente degradáveis $(A+B)$ assim como a degrada- 
bilidade efetiva $(D E)$ das dietas aumentaram quando a sacharina foi incluída (Tabela 5). O hibisco somente afetou a degradabilidade efetiva $(D E)$.

Nenhuma das variáveis estudadas para a degradação da proteína bruta do capim foi afetada pelo hibisco. Somente foi observado o efeito da sacharina no aumento da fração potencialmente degradável $(A+B)$, mostrado na Tabela 6.

As taxas de degradação da proteína bruta da sacharina, do hibisco e do concentrado são apresentadas na Tabela 7. Para a degradabilidade de proteína, a sacharina apresentou os maiores valores de solubilidade inicial $(A)$ e de degradabilidade efetiva $(D E)$. O hibisco apresentou os maiores valores da fração insolúvel degradável $(B)$, as mais altas taxas de degradação $(c)$, e ainda apresentou um tempo de colonização discreto $\left(t_{0}\right)$. O concentrado teve os mais elevados valores de degradabilidade potencial da proteína bruta $(A+B)$.

A fração $A$ da proteína bruta da dieta (Tabela 8 ) aumentou por efeito da sacharina. A fração $B$ também foi afetada, tanto por inclusão da sacharina como do hibisco, além de ter apresentado efeito da interação: a adição de hibisco aumentou a fração $B$, mas a inclusão de sacharina, ou de sacharina e hibisco, não afetou essa fração.

TABELA 4. Constantes de degradação ruminal da MS da sacharina, do hibisco e do concentrado nas dietas à base de capim-estrelaafricana (Cynodon plectostchyus)

\begin{tabular}{lccccccc}
\hline \multirow{2}{*}{ Alimento } & Dieta $^{(1)}$ & \multicolumn{5}{c}{ Variáveis $^{(2)}$} \\
\cline { 3 - 8 } Sacharina & & $\mathrm{A}$ & $\mathrm{B}$ & $\mathrm{A}+\mathrm{B}$ & $\mathrm{c}$ & $\mathrm{t}_{0}$ & DE \\
& Dieta 3 & 50,79 & 40,24 & 91,02 & 0,0221 & $-15,10$ & 61,48 \\
\multirow{3}{*}{ Hibisco } & Dieta 4 & 47,64 & 38,23 & 85,87 & 0,0373 & $-11,93$ & 62,63 \\
& Dieta 2 & 22,90 & 62,29 & 85,19 & 0,0627 & 2,73 & 54,45 \\
Concentrado & Dieta 4 & 23,79 & 58,93 & 82,73 & 0,0803 & 1,83 & 56,90 \\
& Dieta 1 & 41,15 & 56,89 & 98,04 & 0,0387 & $-10,50$ & 62,11 \\
& Dieta 2 & 42,22 & 54,07 & 96,29 & 0,0373 & $-10,28$ & 63,05 \\
& Dieta 3 & 40,15 & 57,73 & 97,88 & 0,0312 & $-8,18$ & 60,59 \\
& Dieta 4 & 41,46 & 55,94 & 97,40 & 0,0277 & $-10,40$ & 59,26 \\
\hline
\end{tabular}

(1) Dieta 1: $75 \%$ pasto $+25 \%$ concentrado; dieta $2: 50 \%$ pasto $+25 \%$ concentrado $+25 \%$ hibisco; dieta $3: 50 \%$ pasto $+25 \%$ concentrado $+25 \%$ sacharina; e dieta $4: 25 \%$ pasto $+25 \%$ concentrado $+25 \%$ hibisco $+25 \%$ sacharina.

(2) A: fração prontamente solúvel (\%); B: fração insolúvel fermentecível (\%); $\mathrm{A}+\mathrm{B}$ : fração potencialmente degradável (\%); c: taxa de degradação; $\mathrm{t}$ : tempo de colonização (h); DE: degradabilidade efetiva (\%).

TABELA 5. Constantes de degradação ruminal da MS das dietas à base de capim-estrela-africana (Cynodon plectostchyus) suplementada com hibisco ou sacharina

\begin{tabular}{|c|c|c|c|c|c|c|}
\hline \multirow{2}{*}{$\operatorname{Dieta}^{(1)}$} & \multicolumn{6}{|c|}{ Variáveis $^{(2)}$} \\
\hline & A & $\mathrm{B}$ & $\mathrm{A}+\mathrm{B}$ & $\mathrm{c}$ & $\mathrm{t}_{0}$ & $\mathrm{DE}$ \\
\hline Dieta 1 & 24,40 & 47,67 & 72,07 & 0,0357 & $-4,23$ & 42,00 \\
\hline Dieta 2 & 26,89 & 51,24 & 78,13 & 0,0376 & $-3,08$ & 46,62 \\
\hline Dieta 3 & 34,74 & 47,35 & 82,07 & 0,0294 & $-6,50$ & 50,03 \\
\hline Dieta 4 & 35,08 & 47,12 & 82,22 & 0,0398 & $-5,05$ & 53,72 \\
\hline $\begin{array}{l}\text { EPM }^{(3)} \\
\text { Efeitos }\end{array}$ & 1,72 & 1,07 & 1,30 & 0,0047 & 0,81 & 1,19 \\
\hline Sacharina & $* *$ & ns & $* *$ & ns & $*$ & $* * *$ \\
\hline Hibisco & ns & ns & ns & ns & ns & $*$ \\
\hline Sacharina $x$ hibisco & ns & ns & ns & ns & ns & ns \\
\hline
\end{tabular}

(1) Dieta 1: $75 \%$ pasto $+25 \%$ concentrado; dieta $2: 50 \%$ pasto $+25 \%$ concentrado $+25 \%$ hibisco; dieta $3: 50 \%$ pasto $+25 \%$ concentrado $+25 \%$ sacharina; e dieta $4: 25 \%$ pasto $+25 \%$ concentrado $+25 \%$ hibisco $+25 \%$ sacharina.

(2) A: fração prontamente solúvel (\%); B: fração insolúvel fermentecível (\%); A+B: fração potencialmente degradável (\%); c: taxa de degradação; $\mathrm{t}_{0}$ : tempo de colonização (h); DE: degradabilidade efetiva (\%).

(3) $\mathrm{EPM}=$ erro padrão da média; $\mathrm{ns}=$ não significativo $(\mathrm{P}>0,05)$; * $=\mathrm{P}<0,05 ; * *=\mathrm{P}<0,01 ; * * * \mathrm{P}<0,001$. 
TABELA 6. Constantes de degradação ruminal da PB do capim-estrela-africana (Cynodon plectostchyus) por animais alimentados com as quatro dietas ${ }^{(1)}$ experimentais

\begin{tabular}{|c|c|c|c|c|c|c|}
\hline \multirow{2}{*}{ Alimentação dos animais ${ }^{(1)}$} & \multicolumn{6}{|c|}{ Variáveis $^{(2)}$} \\
\hline & A & B & $\mathrm{A}+\mathrm{B}$ & $\mathrm{c}$ & $\mathrm{t}_{0}$ & $\mathrm{DE}$ \\
\hline Dieta 1 & 37,67 & 38,09 & 75,76 & 0,0381 & 1,83 & 52,24 \\
\hline Dieta 2 & 39,43 & 39,90 & 79,33 & 0,0270 & 1,18 & 51,57 \\
\hline Dieta 3 & 45,79 & 40,78 & 86,57 & 0,0387 & $-2,28$ & 61,48 \\
\hline Dieta 4 & 46,17 & 38,41 & 84,58 & 0,0298 & $-4,95$ & 58,90 \\
\hline $\begin{array}{l}\text { EPM }^{(3)} \\
\text { Efeito }\end{array}$ & 5,10 & 3,69 & 1,73 & 0,0042 & 5,29 & 4,53 \\
\hline Sacharina & ns & ns & $* *$ & ns & Ns & ns \\
\hline Hibisco & ns & ns & ns & ns & Ns & ns \\
\hline Sacharina $x$ hibisco & ns & ns & ns & ns & Ns & ns \\
\hline
\end{tabular}

(1) Dieta 1: $75 \%$ pasto $+25 \%$ concentrado; dieta $2: 50 \%$ pasto $+25 \%$ concentrado $+25 \%$ hibisco; dieta $3: 50 \%$ pasto $+25 \%$ concentrado $+25 \%$ sacharina; e dieta $4: 25 \%$ pasto $+25 \%$ concentrado $+25 \%$ hibisco $+25 \%$ sacharina.

(2) A: fração prontamente solúvel (\%); B: fração insolúvel fermentecível (\%); A+B: fração potencialmente degradável (\%); c: taxa de degradação; $\mathrm{t}_{0}$ : tempo de colonização (h); DE: degradabilidade efetiva (\%).

(3) $\mathrm{EPM}=$ erro padrão da média; ns $=$ não significativo $(\mathrm{P}>0,05)$; ** $=\mathrm{P}<0,01$.

TABELA 7. Constantes de degradação ruminal da PB da sacharina, do hibisco e do concentrado nas dietas à base de capim-estrelaafricana (Cynodon plectostchyus)

\begin{tabular}{|c|c|c|c|c|c|c|c|}
\hline \multirow{2}{*}{ Alimentos } & \multirow{2}{*}{$\operatorname{Dietas}^{(1)}$} & \multicolumn{6}{|c|}{ Variáveis $^{(2)}$} \\
\hline & & A & B & $\mathrm{A}+\mathrm{B}$ & $\mathrm{c}$ & $\mathrm{t}_{0}$ & $\mathrm{DE}$ \\
\hline \multirow[t]{2}{*}{ Sacharina } & Dieta 3 & 62,41 & 33,08 & 95,49 & 0,0320 & $-5,93$ & 73,87 \\
\hline & Dieta 4 & 60,80 & 33,07 & 93,87 & 0,0512 & $-5,58$ & 76,03 \\
\hline \multirow[t]{2}{*}{ Hibisco } & Dieta 2 & 26,09 & 69,17 & 95,26 & 0,0708 & 3,83 & 63,58 \\
\hline & Dieta 4 & 36,52 & 57,75 & 94,26 & 0,1032 & $-0,78$ & 73,56 \\
\hline \multirow[t]{4}{*}{ Concentrado } & Dieta 1 & 51,75 & 45,81 & 97,55 & 0,0254 & $-15,22$ & 65,55 \\
\hline & Dieta 2 & 52,42 & 44,36 & 96,77 & 0,0283 & $-12,33$ & 66,85 \\
\hline & Dieta 3 & 56,50 & 43,50 & 99,99 & 0,0159 & $-17,43$ & 65,49 \\
\hline & Dieta 4 & 55,25 & 44,75 & 99,99 & 0,0146 & $-19,33$ & 64,07 \\
\hline
\end{tabular}

(1) Dieta 1: $75 \%$ pasto $+25 \%$ concentrado; dieta 2: $50 \%$ pasto $+25 \%$ concentrado $+25 \%$ hibisco; dieta $3: 50 \%$ pasto $+25 \%$ concentrado $+25 \%$ sacharina; e dieta $4: 25 \%$ pasto $+25 \%$ concentrado $+25 \%$ hibisco $+25 \%$ sacharina.

(2) A: fração prontamente solúvel (\%); B: fração insolúvel fermentecível (\%); A+B: fração potencialmente degradável (\%); c: taxa de degradação; t tempo de colonização (h); DE: degradabilidade efetiva (\%).

TABELA 8. Constantes de degradação ruminal da PB das dietas à base de capim-estrela-africana (Cynodon plectostchyus) suplementada com hibisco ou sacharina

\begin{tabular}{|c|c|c|c|c|c|c|}
\hline \multirow{2}{*}{$\operatorname{Dietas}^{(1)}$} & \multicolumn{6}{|c|}{ Variáveis $^{(2)}$} \\
\hline & A & B & $\mathrm{A}+\mathrm{B}$ & $\mathrm{c}$ & $\mathrm{t}_{0}$ & $\mathrm{DE}$ \\
\hline$\overline{\text { Dieta } 1}$ & 41,10 & 37,12 & 80,22 & 0,0361 & $-0,40$ & 55,65 \\
\hline Dieta 2 & 40,30 & 46,01 & 86,33 & 0,0392 & 0,18 & 58,53 \\
\hline Dieta 3 & 53,88 & 38,45 & 92,28 & 0,0279 & $-6,45$ & 65,81 \\
\hline Dieta 4 & 52,84 & 37,97 & 90,81 & 0,0402 & $-6,25$ & 68,03 \\
\hline $\begin{array}{l}\mathrm{EPM}^{(3)} \\
\text { Efeito }\end{array}$ & 2,93 & 1,21 & 1,73 & 0,0042 & 2,29 & 2,72 \\
\hline Sacharina & $* *$ & $*$ & $* *$ & ns & $*$ & $*$ \\
\hline Hibisco & ns & $*$ & ns & ns & ns & ns \\
\hline Sacharina $x$ hibisco & ns & $* *$ & ns & ns & ns & ns \\
\hline
\end{tabular}

${ }^{(1)}$ Dieta $1: 75 \%$ pasto $+25 \%$ concentrado; dieta $2: 50 \%$ pasto $+25 \%$ concentrado $+25 \%$ hibisco; dieta $3: 50 \%$ pasto $+25 \%$ concentrado $+25 \%$ sacharina; e dieta $4: 25 \%$ pasto $+25 \%$ concentrado $+25 \%$ hibisco $+25 \%$ sacharina.

(2) A: fração prontamente solúvel (\%); B: fração insolúvel fermentecível (\%); A+B: fração potencialmente degradável (\%); c: taxa de degradação; $\mathrm{t}_{0}$ : tempo de colonização (h); DE: degradabilidade efetiva (\%).

(3) $\mathrm{EPM}=$ erro padrão da média; $\mathrm{ns}=$ não significativo $(\mathrm{P}>0,05)$; * $=\mathrm{P}<0,05 ; * *=\mathrm{P}<0,01$. 
O grau e a extensão da degradação dos alimentos podem estar relacionados ao crescimento microbiano. Por um lado, RUSSEL et al. (1980) mostraram que a infusão de ureia aumentou proporcionalmente as quantidades de bactérias associadas e a concentração total de AGCC, mas isso pareceu ter pouco ou nenhum impacto sobre a degradação ruminal. Esse fato sugere que a concentração de $\mathrm{N}$ amoniacal para o máximo crescimento microbiano difere da máxima degradação dos alimentos. Por outro lado, WALLACE (1979) observou que o aumento da degradação da MS e da PB foi acompanhado do aumento do crescimento bacteriano, quando a concentração de $\mathrm{N}$ amoniacal subiu de 9,7 para $21,4 \mathrm{mg} / \mathrm{dl}$.

A disponibilidade de energia tem uma influência modificadora importante sobre a degradação ruminal dos alimentos. Assim, como o número de bactérias pode aumentar em resposta ao aumento da concentração de amônio, a degradação da fibra dentro dos sacos de nylon não foi afetada, pois a entrada de bactérias celulolíticas foi limitada devido ao ataque de bactérias ao material fibroso no rúmen. A produção de AGCC no rúmen está de certo modo relacionada ao $\mathrm{pH}$ ruminal, o qual é um dos reguladores importantes da eficiência da síntese microbiana e da absorção de aminoácidos (RUSSELL \& DOMBROWSKI, 1980).

Aumentando-se o teor de PB da dieta pode haver não apenas maior produção animal (WU \& SETTER, 2000), mas também aumento das concentrações de $\mathrm{N}$ amoniacal ruminal e de $\mathrm{N}$ ureico no sangue, e, por consequência, podem ocorrer maiores perdas de $\mathrm{N}$ na urina (CASTILLO et al., 2001). A perda de $\mathrm{N}$ no rúmen foi relatada por TAMMINGA (1992) como o maior contribuidor para as perdas de $\mathrm{N}$ do animal como um todo. Se não for usada para a síntese de proteína microbiana, a proteína degradável no rúmen pode ser convertida em $\mathrm{N}$ amoniacal. Este, por sua vez, pode ser absorvido pela parede ruminal, detoxificam a ureia no fígado (LOBLEY et al., 1995) e gradualmente ser excretado via urina. Certa quantidade da proteína degradável no rúmen pode passar ao rúmen e contribuir para o fluxo duodenal de aminoácidos e peptídeos (CHOI et al., 2002). O excesso de $\mathrm{N}$ amoniacal da proteína degradável no rúmen aumenta a síntese de proteína microbiana dos ruminantes (HRISTOV et al., 2004). Esse excesso de proteína degradável da dieta dos ruminantes não pode ser utilizado eficientemente para a síntese de proteína microbiana e será perdido em grande quantidade através da excreção de $\mathrm{N}$ urinário. As bactérias mistas do rúmen produzem menos metano e amônia quando o $\mathrm{pH}$ é menor que 6,0 (ERFLE et al., 1982).

\section{CONCLUSÃO}

A inclusão de hibisco e de sacharina aumentou a degradação das dietas à base de pasto a que foram submetidos os tourinhos. Ao incluir-se essas forragens, junto com o concentrado, melhorou-se o comportamento ruminal dos animais. Por tais motivos, considera-se possível a substituição parcial do concentrado empregado na suplementação de ruminantes quando os alimentos referidos são disponíveis, o que representa um ganho para o pecuarista, já que os grãos normalmente são comprados. Assim sendo, considera-se essa alternativa alimentar viável para melhorar a produção animal em regiões tropicais.

\section{REFERENCIAS}

ALAYÓN, J. A.; RAMÍREZ, A. L.; KU-VERA, J. Intake, rumen digestion, digestibility and microbial nitrogen supply in sheep fed Cynodon nlemfuensis supplemented with Gliricidia sepium. Agroforestry System, v. 41, p. 115-126, 1998.

ARANDA-IBÁÑEZ, E. M.; OSORIO, A. M. M. La alimentación de los animales de la rejeguería. In: OSORIO, A. M. M. (Ed.). Producción bovina de doble propósito en el trópico: la rejeguería. v. 2. Villahermosa: Instituto para el Desarrollo de Sistemas de Producción del Trópico Húmedo de Tabasco (ISPROTAB), 2003. p. 48-69. Disponível em: <http://www.itescam.edu.mx/principal/ sylabus/fpdb/recursos/r32707.PDF>. Acesso em: 17 mar. 2011.

BLAXTER, K. L. The energy metabolism of ruminants. London: Hutchison and Co. Ltd, 1962. 329 p.

CASTILLO, A. R.; KEBREAB, R. E.; BEEVER, D. E.; BARBI, J. H.; SUTTON, H. C.; KIRBY, H. C.; FRANCE, J. The effect of protein supplementation on nitrogen utilization in lactating dairy cows feed grass silage diets. Journal of Animal Science, v. 79, p. 247-253, 2001.

CECAVA, M. J.; MERCHEN, N. R.; BERGER, L. L.; PAHEY JR., G. C. Intestinal supply of amino acids in sheep fed alkaline hydrogen peroxide-treated wheat straw-based diets supplemented with soybean meal or combinations of corn gluten meal and blood meal. Journal of Animal Science, v. 68, p. $467,1990$. 
CECAVA, M. J.; MERCHEN, N. R.; BERGER, L. L.; MACKIE, R. L.; PAHEY JR., G. C. Effects of dietary energy level and protein source on nutrient digestion and ruminal nitrogen metabolism in steers. Journal of Animal Science, v. 69, p. 2.230-2.243, 1991.

CHOI, C. W.; VANHATALO, A.; AHVENJARVI, S.; HUHTANEN, P. Effects on several protein supplements on flow of soluble non-ammonia nitrogen from the forestomach and milk production in dairy cows. Animal Feed Science and Technology, v. 102, p. 15-33, 2002.

COTTA, M. A.; RUSSELL, J. B. The effects of peptides and amino acids on deficiency of rumen bacterial protein synthesis in continuous culture. Journal of Dairy Science, v. 65, p. 226, 1982.

ERWIN, E. S.; MARCO, G. J.; EMERY, E. M. Volatile fatty acid analysis of blood and rumen fluid by gas chromatography. Journal of Dairy Science, v. 44, p. 1.768-1.776, 1961.

ELÍAS, A.; LEZCANO, O.; LEZCANO, P.; CORDERO, J.; QUINTANA L. Reseña descriptiva sobre el desarrollo de una tecnología de enriquecimiento proteico en la caña de azúcar mediante fermentación en estado sólido (Sacharina). Revista Cubana de Ciencia Agricola, v. 24, n. 1, p.1-13, 1990.

ERFLE, J. D.; BOILA, R. J.; TEATHER, R. M.; MAHADEVAN, S.; SAUER, F. D. Effect of $\mathrm{pH}$ on fermentation and protein degradation by rumen microorganism in vitro. Journal of Dairy Science, v. 65, p. 1.457-1.464, 1982.

HESPELL, R. B. Efficiency of growth by ruminal bacteria. Federation Proceedings, v. 38, p. 2.707, 1979.

HRISTOV, A. N.; GRANDEEN, K. L.; ROPP, J. K.; McGUIRE, M. A. Effect of sodium laurate on ruminal fermentation and utilization of ruminal ammonia nitrogen for milk protein synthesis in dairy cows. Journal of Dairy Science, v. 87, p. 1.820-1.831, 2003.

HRISTOV, A. N.; ETTER, R. P.; ROPP, J. K.; GRANDEEN, K. L. Effect of dietary crude protein level and degradability on ruminal fermentation and nitrogen utilization in lactating dairy cows. Journal of Animal Science, v. 82, p.3219-3229, 2004.

HUNGATE, R. E. The rumen and its microbes. New York: Academic Press, 1966. 533 p.

LOBLEY, G. E.; CONNELL, A.; LOMAX, M. A.; BROWN, D. S.; MILNE, E.; CALDER, A. G.; FARNINGHAM, D. A. H. Hepatic detoxification of ammonia in the ovine liver: possible consequences for amino acids catabolism. British Journal of Nutrition, v. 73, p. $667-685,1995$.

McCULLOUGH, H. The determination of ammonia in whole blood by a direct colorimetric method. Clinical Chemistry Acta, v. 17, p. 297-304, 1967.
McDONALD, I. A revised model for estimation of protein degradability in the rumen. Journal of Agricultural Science, v. 93, p. 251-252, 1981.

MEHREZ, A. Z.; ØRSKOV, E. R.; MCDONALD, I. Rates of rumen fermentation in relation to ammonia concentration. British Journal of Nutrition, v. 38, p. 437, 1977.

ØRSKOV, E. R.; McDONALD, P. The estimation of protein degradability in the rumen from incubation measurements weighted according to rate of passage. Journal of Agricultural Science, v. 92 , p. 499-503, 1979.

ØRSKOV, E. R.; HOVELL, F. D. D.; MOULD, F. The use of the nylon technique for the evaluation of feedstuffs. Tropical Animal Production, v. 5, p. 195-213, 1980.

ROHR, K.; LEBZEIN, P.; SCHAFFT, H.; SCHULZ, E. Prediction of duodenal flow of non-ammonia nitrogen and amino acid nitrogen in dairy cows. Livestock Production Science, v. 14, n. 1, p. 29-40, 1986.

RUSSELL, J. B. The importance of $\mathrm{pH}$ in the regulation of ruminal acetate to propionate ratio and methane production in vitro. Journal of Dairy Science, v. 81, p. 3.222-3.230, 1998.

RUSSELL, J. B.; DOMBROWSKI, D. B. Effect of $\mathrm{pH}$ on the efficiency of growth by pure cultures of rumen bacteria in continuous culture. Applied Environmental Microbiology, v. 39, p. $604,1980$.

SAS INSTITUTE. The SAS system for Windows. Release 8.01. Cary: SAS, 2001.

SCHAEFER, D. M.; DAVIS, C. L.; BRYANT, M. P. Ammonia saturation constants for predominant species of rumen bacteria. Journal of Dairy Science, v. 63, p. 1.248, 1980.

SLYTER, L.L.; BRYANT, M.P.; WOLIN, M.J. Effect of pH on population and fermentation in a continuously cultured rumen ecosystem. Applied Microbiology, v.14, n.4, p.573-578, 1966.

SONG, M. K.; KENNELLY, J. J. Ruminal fermentation pattern, bacterial population and ruminal degradation of feed ingredients as influenced by ruminal ammonia concentration. Journal of Animal Science, v. 68, p. 1.110-1.120, 1990.

STEEL, R. G. D.; TORRIE, J. H. Principles and procedures of statistics: a biometrical approach. 2. ed. New York: McGraw-Hill Book Co., 1980. 633 p.

TAMMINGA, S. Nutrition management of dairy cows as a contribution to pollution control. Journal of Dairy Science, v. 75, p. 345-357, 1992. 
WALLACE, R. J. Effect of ammonia concentration on the composition, hydrolytic activity and nitrogen metabolism of the rumen. Journal of Applied Bacteriology, v. 47, p. 443, 1979.
WOLIN, M. J. A theorical rumen fermentation balance. Journal of Dairy Science, v. 43, p. 1.452-1.459. 1960.

WU, Z.; SETTER, L. D. Milk production during the complete lactation of dairy cows fed diets containing different amounts of protein. Journal of Dairy Science, v. 83, p. 1.042-1.051, 2000.

Submetido em: $1^{\circ}$ out. 2008. Aceito em: 14 jan. 2011. 